\title{
Proteínas de reserva de acessos de coleção nuclear de arroz
}

\author{
Ricardo Diógenes Dias Silveira(1), Karina Freire d'Eça Nogueira Santos ${ }^{(1)}$, \\ Claudia Cristina Garcia Martim Didonet( ${ }^{(2)}$, Agostinho Dirceu Didonet ${ }^{(1)}$ e Claudio Brondani(1)
}

${ }^{(1)}$ Embrapa Arroz e Feijão, Rodovia GO-462, Km 12, Zona Rural, Caixa Postal 179, CEP 75375-000 Santo Antônio de Goiás, GO.
E-mail: ricardo@cnpaf.embrapa.br, karina@cnpaf.embrapa.br, didonet@cnpaf.embrapa.br, brondani@cnpaf.embrapa.br (2)Universidade Estadual
de Goiás, Unidade de Ciências Exatas e Tecnológicas, BR 153, Km 98, Jardim Arco Verde, CEP 75001-970 Anapolis, GO. E-mail: ccdidonet@gmail.com

Resumo - O objetivo deste trabalho foi quantificar o conteúdo de proteína total de reserva dos 550 acessos da Coleção Nuclear de Arroz da Embrapa (CNAE), e avaliar o perfil proteico dos 20 acessos com maior teor de proteína em SDS-PAGE. Foi encontrado alto teor de proteína total de reserva $(\geq 12,0 \%)$ em 103 acessos da CNAE, teor médio (11,9 a 9,0\%) em 309 acessos e teor baixo $(\leq 8,9 \%)$ em 138 acessos. Seis dos 20 acessos com maior teor de proteína de reserva apresentaram um padrão qualitativo diferencial de glutelina, que é a fração proteica de reserva mais abundante do grão de arroz. Há ampla variabilidade para o teor de proteína total de reserva do grão de arroz nos acessos da CNAE, a qual pode ser explorada por programas de melhoramento genético para aumentar o valor nutricional do arroz consumido no Brasil.

Termos para indexação: Oryza sativa, conteúdo de proteínas, recursos genéticos, valor nutricional.

\section{Storage proteins in accessions of a rice core collection}

\begin{abstract}
The objective of this work was to quantify the total storage protein content of 550 accessions from Coleção Nuclear de Arroz da Embrapa (Embrapa Rice Core Collection - CNAE), and to evaluate the SDS-PAGE profile of the 20 accessions that showed the highest storage protein content. High storage protein content was found in 103 CNAE accessions $(\geq 12.0 \%)$, intermediate content $(11.9$ to $9.0 \%)$ in 309 , and low protein content $(\leq 8.9 \%)$ in 138 . Six out of the 20 accessions with the highest storage protein content showed a differential profile for glutelin, which is the most abundant rice storage protein fraction. There is a large variability of rice storage protein in CNAE accessions, which can be explored in breeding programs to increase the nutritional value of the rice consumed in Brazil.
\end{abstract}

Index terms: Oryza sativa, protein content, genetic resources, nutritional value.

\section{Introdução}

O arroz (Oryza sativa L.) é um alimento essencial para mais de $50 \%$ da população mundial, fornecendo $20 \%$ da energia e $15 \%$ da proteína de que cada indivíduo necessita por dia (Pereira et al., 2005).

O valor nutricional do arroz beneficiado polido está relacionado principalmente ao seu conteúdo proteico. A proteína do arroz é considerada de boa qualidade porque contém os oito aminoácidos essenciais ao homem e, quando combinada com a proteína de reserva de espécies leguminosas, como o feijão, resulta em uma mistura de alto valor proteico. Adicionalmente, o arroz é uma excelente fonte de carboidratos complexos, contém quantidades desprezíveis de gordura e é livre de colesterol (Castro et al., 1999). As proteínas presentes no grão (endosperma e embrião) são classificadas como de reserva, e são acumuladas em grandes quantidades durante o desenvolvimento da semente. Estas são utilizadas durante a germinação e, por este motivo, são sintetizadas somente na semente e não em outros tecidos. Além disso não possuem outra atividade funcional fora da semente, onde são depositadas principalmente em organelas especiais chamadas de corpos proteicos (Shewry\& Halford, 2002).

O arroz é um dos cereais com os menores teores proteicos: entre 5-10\% do conteúdo total do grão (Cagampang et al., 1966). Recentemente, Jugran et al. (2010) caracterizaram 48 variedades de arroz coletadas na Índia e observaram que os teores proteicos variaram entre 1,65 e 9,33\%. Porém, alguns estudos demonstram, por meio de análise genética, que existem diferenças significativas no armazenamento de proteínas nos grãos de arroz, principalmente entre acessos de regiões geográficas distintas (Kameswara Rao \& Jackson, 1996, 1997). A variação genética no conteúdo proteico fornece as bases para o melhoramento genético do arroz com vistas ao aumento de seu valor nutricional (Lu et al., 2008). 
As proteínas de reserva, no arroz, estão divididas em quatro frações principais, de acordo com a solubilidade: albuminas, solúveis em água; globulinas, solúveis em sais; prolaminas, solúveis em álcool; e glutelinas, solúveis em soluções ácidas ou básicas (Osborne 1924; Shotwell \& Larkins, 1989). A fração dominante é a glutelina, com aproximadamente $51 \%$ da proteína total do grão polido, seguida pela prolamina, com 34\%, globulina, com 11\%, e albumina, com 4\% (Krishnan $\&$ White, 1995). A diferença de percentagem de cada fração encontrada em diferentes cultivares varia de acordo com a base genética do genótipo avaliado, condições ambientais e métodos analíticos utilizados (Huebner et al., 1990; Krishnan \& White, 1995).

Estima-se que existam mais de 120.000 acessos de arroz armazenados em bancos de germoplasma no mundo (Khush, 1997). Somente o banco de germoplasma do International Rice Research Institute (IRRI) possui mais de 100.000 acessos de arroz armazenados. Contudo, apesar dos esforços para coleta e conservação da variabilidade genética do arroz, muito pouco se conhece a respeito da quantidade e qualidade das proteínas de reserva da espécie. Por causa do tamanho das coleções de germoplasma de arroz, o ponto de partida para determinar a variação nos valores do teor de proteína total de reserva deve ser iniciado por uma amostragem dessas coleções, e a maneira mais adequada para amostrar grandes coleções de germoplasma é por meio do estabelecimento de coleções nucleares (Van Hintum et al., 2000).

Conceitualmente, uma coleção nuclear representa o máximo da variabilidade genética presente na coleção completa de germoplasma, reunida no menor número de indivíduos (Frankel, 1984). O objetivo deste trabalho foi realizar a análise quantitativa e qualitativa da proteína total de reserva dos acessos da Coleção Nuclear de Arroz da Embrapa.

\section{Material e Métodos}

Foram utilizadas amostras de sementes dos 550 acessos da Coleção Nuclear de Arroz da Embrapa (CNAE). Esta coleção foi estabelecida em 2002, e conta com 550 acessos divididos em três estratos: variedades tradicionais (VT), oriundas de expedições de coletas de germoplasma no Brasil; linhagens e cultivares brasileiras (LCB), desenvolvidas por programas brasileiros de melhoramento genético de arroz; e linhagens e cultivares introduzidas
(LCI), desenvolvidas por programas estrangeiros de melhoramento genético de arroz (Abadie et al., 2005). A CNAE foi elaborada com base em uma coleção de aproximadamente 10.000 acessos de arroz, armazenados no Banco Ativo de Germoplasma da Embrapa (Coleção Nuclear de Arroz da Embrapa, 2010).

As amostras proteicas foram coletadas com base no processamento das sementes, as quais foram secas, descascadas, moídas e desengorduradas com acetona (PA). A partir de $10 \mathrm{mg}$ dessa farinha, foi extraída a proteína total de cada genótipo, adicionando-se 250 $\mu \mathrm{L}$ de $\mathrm{NaOH} 0,1 \mathrm{~mol} \mathrm{~L}^{-1}$, e agitando por 1 hora. Após esse período, as amostras foram centrifugadas por 8 minutos a $13.000 \mathrm{rpm}$. Esse procedimento foi realizado duas vezes, para extrair maior quantidade de proteína total. Foram realizadas quatro extrações independentes por amostra. Ao final, as amostras com os extratos proteicos foram armazenadas a $-20^{\circ} \mathrm{C}$.

A quantificação de proteínas dos extratos foi realizada pelo método de Bradford (1976). A partir de cada uma das quatro repetições de cada genótipo, foram preparadas triplicatas das amostras para serem quantificadas por espectrofotometria $(595 \mathrm{~nm})$. Para isto utilizaram-se $10 \mu \mathrm{L}$ do extrato proteico e $90 \mu \mathrm{L}$ de água destilada. A curva de calibração foi obtida com a leitura de soro albumina bovina (BSA) nas concentrações de 2,5 a $40 \mu \mathrm{g} \mu \mathrm{L}^{-1}$.

A concentração das proteínas totais foi calculada com base nos valores de densidade óptica obtidos pelo espectrofotômetro. Os dados de quantificação dos extratos de proteínas foram submetidos à análise de variância em delineamento inteiramente casualizado com três repetições por amostra, pelos programas Genes (Cruz, 1997) e SAS (SAS Institute, 1995). O teste de agrupamento das médias entre acessos e entre grupos de acessos foi realizado pelo teste de Scott-Knott, a 5\% de probabilidade. Foram obtidos gráficos de distribuição de frequência com todos os acessos da CNAE agrupados e também para cada sistema de origem (VT, LCB ou LCI) e sistema de cultivo dos acessos (irrigado, sequeiro ou facultativo), utilizando o Microsoft Office Excel, versão 2007.

Os vinte acessos com maior teor proteico foram avaliados em SDS-PAGE, de acordo com procedimentos de Laemmli (1970). Os géis eram constituídos pelas concentrações de $4,5 \%$ e $14,0 \%$ para a parte concentradora e separadora, respectivamente. Foram utilizadas $20 \mathrm{mg}$ de farinha e $350 \mu \mathrm{L}$ de 


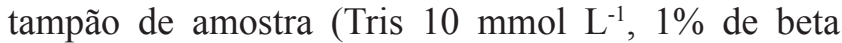
mercaptoetanol, $2 \%$ de SDS, $3 \%$ de glicerol e azul de bromofenol). As amostras foram então fervidas por 10 min, para desnaturação e, em seguida, submetidas à eletroforese a $80 \mathrm{~mA}$, por 1 hora, e $55 \mathrm{~mA}$, por 3 horas e $30 \mathrm{~min}$.

Os géis foram corados em solução de Coomassie Brilliant Blue R250 (0,05\%), metanol (50\%), ácido acético (10\%) e água (40\%), e descorados com solução de ácido acético (10\%), metanol (45\%) e água (45\%). Os géis foram fotografados por máquina digital, e as imagens padronizadas pelo programa Paint Shop Pro versão 7.01 (Jasc Software). Com base nas imagens, foi possível comparar o perfil proteico das amostras com o programa DNA Simdex3 beta release (Scott Archer and GenetX), e então determinou-se a massa molecular de cada banda, pelo posicionamento das bandas do marcador de peso molecular padrão LMW Calibration Kit For SDS Electrophoresis (GE Healthcare do Brasil Ltda., São Paulo, SP).

\section{Resultados e Discussão}

Os teores de proteína total de reserva do grão de arroz apresentaram diferença altamente significativa $(p<0,01)$, entre os 550 genótipos da CNAE. A alta variabilidade do teor proteico dentro da CNAE foi constatada, também, pela razão entre o coeficiente de variação genético $(3,93)$ e o coeficiente de variação experimental $(3,53)-\mathrm{CVg} / \mathrm{CVe}-$ superior a 1. Porém, quando os acessos foram divididos em grupos de acordo com a origem dos genótipos (VT, LCI e LCB), ou em grupos de acordo com o sistema de cultivo (irrigado, sequeiro ou facultativo), não houve diferença significativa na comparação de médias. Isso indica que os genótipos pertencentes a esses grupos não possuem um padrão de teor de proteína de reserva que possa ser caracterizado como alto ou baixo (Tabela 1). Esse resultado também pode ser observado nos gráficos de distribuição de frequência, que tiveram o formato aproximado de curva normal, sem concentração de acessos nas classes extremas dos histogramas (Figuras 1 e 2).

O teor de proteína total do grão dos 550 acessos da CNAE variou de $4,44 \%$, na variedade tradicional de sequeiro CA780269, a 20,25\%, na linhagem de arroz irrigado da Colômbia CNA0007408, com média de $10,31 \%$ e desvio padrão de $0,21 \%$ (Tabela 1 ). Considerando os valores encontrados, foi possível dividir a CNAE em três grupos de genótipos: 103 acessos com alto teor de proteína (teores maiores ou iguais a 12\%); 309 acessos com teor intermediário de proteína (11,9 a 9\%); e 138 acessos com baixo teor proteico (teores menores ou iguais a 8,9\%). A variação nos teores de proteína na CNAE foi superior à encontrada por Koutroubas et al. (2004), ao avaliar 318 acessos de cinco coleções nucleares de arroz da Europa, com um teor proteico médio de 7,16\% (valores extremos de 4,18 a $11,9 \%$ ).

Tabela 1. Médias dos teores de proteínas de reserva dos grupos de acessos da Coleção Nuclear de Arroz da Embrapa (CNAE).

\begin{tabular}{|c|c|c|c|c|c|}
\hline Grupo de acesso da CNAE ${ }^{(1)}$ & Média & Intervalos de médias & Desvio-padrão & Coeficiente de variação (\%) & Quadrado médio do resíduo \\
\hline Irrigado & 10,52 & $5,96-20,25$ & 2,12 & 3,03 & $0,119^{*}$ \\
\hline LCB irrigado & 10,58 & $5,96-15,92$ & 1,36 & 3,16 & $0,112 * *$ \\
\hline $\mathrm{LCB}$ & 10,36 & $4,81-15,92$ & 1,36 & 2,93 & $0,092 *$ \\
\hline LCB sequeiro & 10,13 & $4,81-13,72$ & 1,38 & 2,75 & $0,078^{*}$ \\
\hline LCI irrigado & 10,54 & $5,96-20,25$ & 1,62 & 3,28 & $0,120^{*}$ \\
\hline LCI & 10,54 & $4,84-20,25$ & 1,53 & 5,80 & $0,352 *$ \\
\hline LCI sequeiro & 9,93 & $4,84-14,45$ & 1,99 & 4,03 & $0,160^{*}$ \\
\hline Sequeiro & 10,13 & $4,44-15,44$ & 1,40 & 3,50 & $0,125^{*}$ \\
\hline Facultativo & 10,41 & $5,96-15,87$ & 1,33 & 4,04 & $0,177^{*}$ \\
\hline VT & 10,29 & $4,44-15,87$ & 1,86 & 4,70 & $0,233^{*}$ \\
\hline VT irrigado & 10,33 & $5,96-13,67$ & 1,30 & 3,36 & $0,120^{*}$ \\
\hline VT irrigado e facultativo & 10,38 & $5,96-15,87$ & 1,31 & 6,42 & $0,443 *$ \\
\hline VT Sequeiro & 10,18 & $4,44-15,44$ & 1,42 & 4,63 & $0,222 *$ \\
\hline VT sequeiro e facultativo & 10,27 & $4,44-15,87$ & 1,39 & 4,58 & $0,180^{*}$ \\
\hline VT sequeiro e irrigado & 10,26 & $4,44-15,44$ & 1,38 & 3,42 & $0,123 *$ \\
\hline Total & 10,31 & $4,44-20,25$ & 0,21 & 3,53 & $0,120 * *$ \\
\hline
\end{tabular}

(1) LCB, linhagens e cultivares brasileiras; LCI, linhagens e cultivares introduzidas; VT, variedades tradicionais. * e **Significativo pelo teste F, a $5 \%$ e $1 \%$ de probabilidade, respectivamente. 


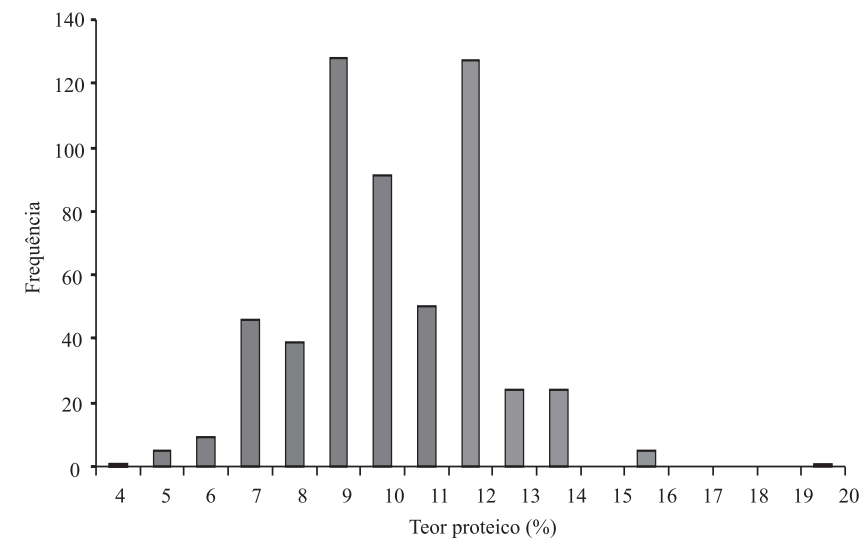

Figura 1. Distribuição de frequência em relação ao teor proteico total dos 550 acessos da Coleção Nuclear de Arroz da Embrapa.
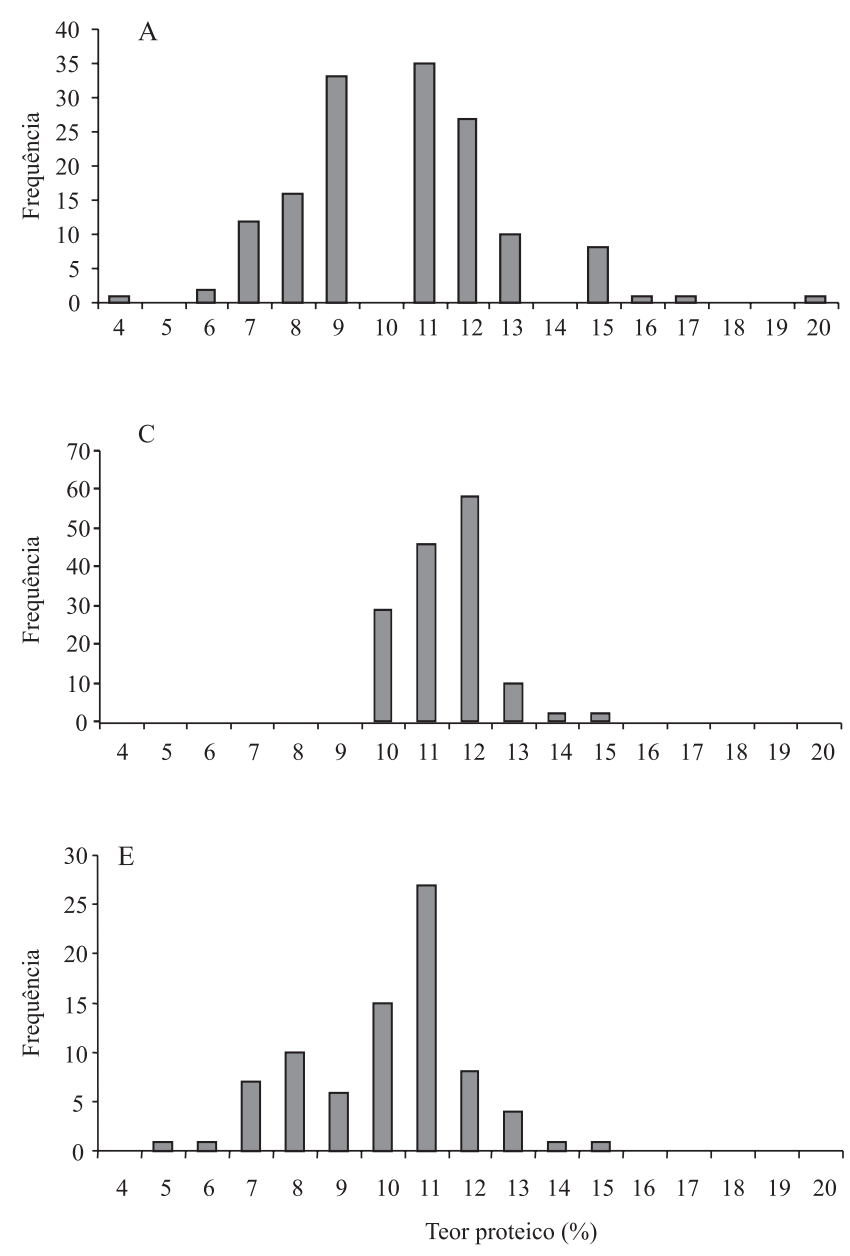

Araújo et al. (2003) caracterizaram o teor proteico de 33 variedades tradicionais de arroz coletadas na Baixada Maranhense, e observaram uma variação de 6,22 a $10,48 \%$, ao passo que as 308 variedades tradicionais da CNAE variaram de 4,44 a $15,44 \%$. Isto demonstra que, independentemente do número de acessos avaliados de VT, essa classe de genótipos apresenta ampla variabilidade genética quanto ao teor proteico de reserva. Considerando os 103 acessos da CNAE com alto teor proteico, $54,37 \%$ são VT, $26,21 \%$ são LCI e $19,42 \%$ são LCB. O conjunto desses acessos pode ser explorado por programas de melhoramento genético do arroz, para o desenvolvimento de cultivares com maior qualidade nutricional. A relação dos 103 acessos
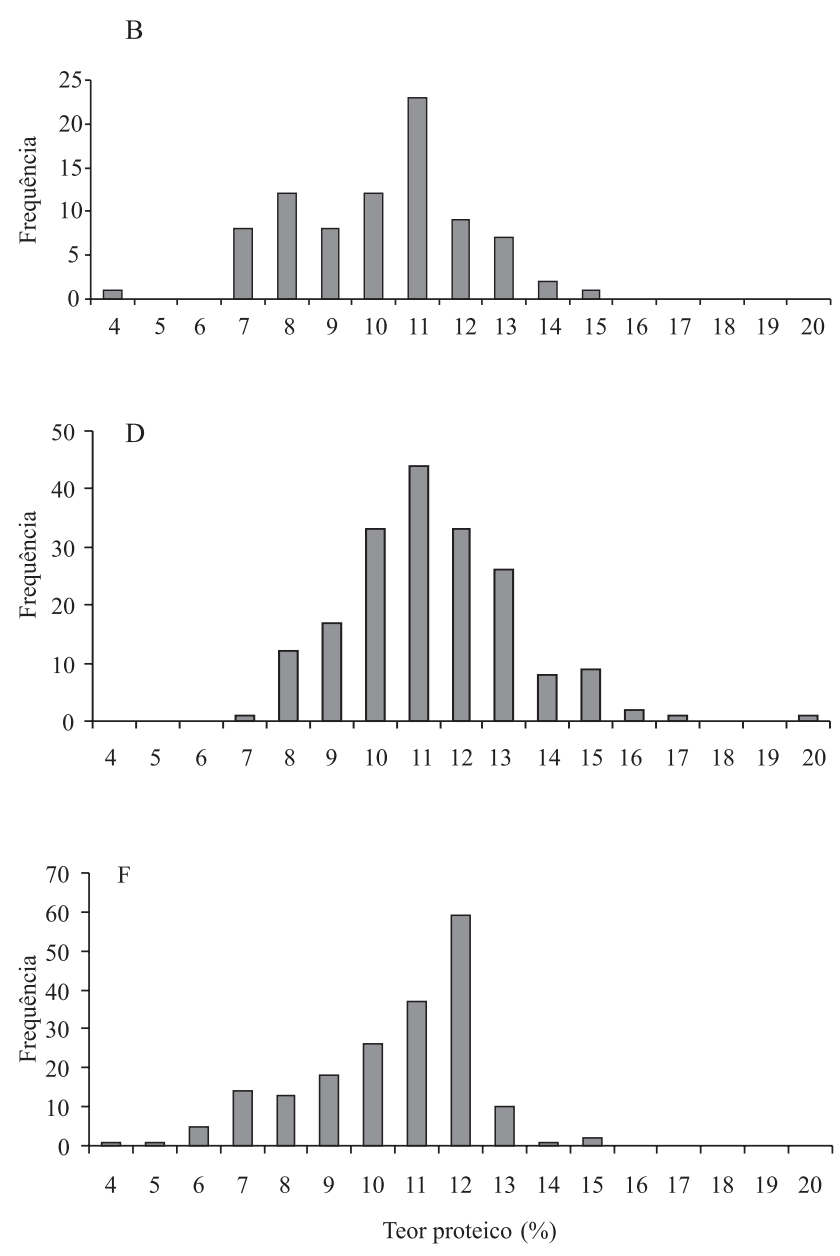

Figura 2. Distribuição de frequência em relação ao teor proteico total dos grupos de acessos da Coleção Nuclear de Arroz da Embrapa, agrupados pela origem e pelo sistema de cultivo. A, acessos com linhagens e cultivares introduzidas (LCI); B, acessos com linhagens e cultivares brasileiras (LCB); C, acessos com variedades tradicionais; D, acessos irrigados; E, acessos sequeiros; F, acessos facultativos. 
pode ser obtida pelo uso da ferramenta CNAE Search (Coleção Nuclear de Arroz da Embrapa, 2010).

Entre os 20 acessos com maior teor proteico, 12 são materiais melhorados no exterior (LCI), cinco são variedades tradicionais (VT) e três são materiais melhorados no Brasil (LCB), o que equivale a afirmar que $75 \%$ dos acessos com maior teor proteico são provenientes de programas de melhoramento genético, apesar dessa característica não ser avaliada na maioria dos programas. A obtenção de um banco de dados de características agronômicas publicamente disponível (Coleção Nuclear de Arroz da Embrapa, 2010), a exemplo do obtido para a CNAE, permite avaliar o comportamento de determinados genótipos para diversas características. Assim, por exemplo, a linhagem CNA000748, que apresentou o maior teor proteico $(20,25 \%)$, teve uma produtividade apenas mediana (3.311 kg ha-1), e um teor de amilose indicativo de grão pegajoso após o cozimento, o que não é desejável para o mercado consumidor no Brasil (Tabela 2). Desse modo, o melhorista pode optar por utilizar esse material como genitor, ciente da necessidade de melhorar outras características agronomicamente importantes.

A análise qualitativa da proteína de reserva dos 20 acessos com maior teor proteico da CNAE permitiu detectar bandas nas faixas de alta (em torno de $90 \mathrm{kDa}$ ), intermediária (entre 36 e $39 \mathrm{kDa}$ ) e baixa massa molecular (menores que $17 \mathrm{kDa}$ ) (Figura 3). Proteínas com massa molecular em torno de 36 e 39 kDa são classificadas como $\alpha$-glutelinas (Juliano, 1985; Oszvald, 2008). Jahan et al. (2001) separaram as $\alpha$-glutelinas em $\alpha-1$ (39 kDa), $\alpha-2$ (38 kDa), $\alpha$-3 (37,5 a $37 \mathrm{kDa}$ ) e $\alpha-4$ (34 a $33 \mathrm{kDa})$. Entre os 20 genótipos, não foram identificadas diferenças nas glutelinas do tipo $\alpha-1, \alpha-2$ e $\alpha-3$. Contudo, foram encontradas glutelinas do tipo $\alpha-4$ nos genótipos CNA0003417, CNA0007408, ELONI, CNA0003195, CNA0004617 e CNA0005853. Esses seis acessos são oriundos de programas de melhoramento do exterior e do sistema de cultivo sequeiro, o que pode indicar uma fonte adicional de variabilidade neste grupo de materiais para ser explorada no programa de melhoramento genético do arroz.

Tabela 2. Informações agronômicas dos 20 acessos da Coleção Nuclear de Arroz da Embrapa com maiores teores de proteína de reserva.

\begin{tabular}{|c|c|c|c|c|c|c|c|c|}
\hline Genótipo & $\begin{array}{c}\text { Teor } \\
\text { protéico }(\%)\end{array}$ & $\begin{array}{l}\text { Sistema de } \\
\text { cultivo }\end{array}$ & Origem & $\begin{array}{l}\text { Produtividade } \\
\left(\mathrm{kg} \mathrm{ha}^{-1}\right)\end{array}$ & $\begin{array}{l}\text { Altura de planta } \\
(\mathrm{cm})\end{array}$ & $\begin{array}{l}\text { Número de } \\
\text { perfilhos }\end{array}$ & $\begin{array}{c}\text { Número de } \\
\text { panículas }\end{array}$ & $\begin{array}{c}\text { Teor de } \\
\text { amilose (\%) }\end{array}$ \\
\hline CNA0007408 & 20,25 & Irrigado & Colômbia (LCI) & 3.311 & 95 & 175 & 164 & 16,87 \\
\hline CICA_7 & 16,59 & Irrigado & Colômbia (LCI) & 6.156 & 110 & 118 & 115 & 65,55 \\
\hline BR IRGA 409 & 15,92 & Irrigado & Brasil (LCB) & 6.100 & 112 & 214 & 132 & 65,81 \\
\hline CA780284 & 15,87 & Facultativo & Brasil (VT) & 5.467 & 116 & 130 & 120 & 25,66 \\
\hline CNA0000923 & 15,64 & Irrigado & México (LCI) & 1.989 & 76 & 156 & 151 & 24,50 \\
\hline CA780391 & 15,44 & Sequeiro & Brasil (VT) & 1.289 & 90 & 177 & 177 & 23,46 \\
\hline CA840026 & 14,73 & Sequeiro & Brasil (VT) & 2.356 & 104 & 126 & 108 & 26,36 \\
\hline CNA0004617 & 14,45 & Sequeiro & Nigéria (LCI) & 3.244 & 78 & 90 & 77 & 24,45 \\
\hline ORYZICA 1 & 14,43 & Irrigado & Colômbia (LCI) & 7.956 & 100 & 171 & 167 & 25,17 \\
\hline CNA0000798 & 14,40 & Irrigado & Colômbia (LCI) & 5.267 & 92 & 197 & 169 & 62,89 \\
\hline CNA0006130 & 14,38 & Irrigado & Brasil (LCB) & 5.485 & 80 & 134 & 127 & 18,36 \\
\hline CNA0003417 & 14,13 & Irrigado & Japão (LCI) & 3.689 & 89 & 155 & 121 & 24,67 \\
\hline CNA0003195 & 14,06 & Irrigado & Egito (LCI) & 3.433 & 64 & 277 & 214 & 18,86 \\
\hline ELONI & 14,04 & Irrigado & Suriname (LCI) & 4.889 & 96 & 205 & 189 & 21,91 \\
\hline CNA0005853 & 14,03 & Irrigado & Rússia (LCI) & 1.795 & 100 & $\mathbf{-}^{(1)}$ & - & 17,00 \\
\hline CA810017 & 13,96 & Sequeiro & Brasil (VT) & 2.522 & 100 & 88 & 69 & 25,68 \\
\hline CNA0008416 & 13,92 & Irrigado & Filipinas (LCI) & 4.422 & 73 & 246 & 209 & 25,62 \\
\hline BR IRGA 413 & 13,91 & Irrigado & Brasil (LCB) & 5.711 & 95 & 168 & 160 & 24,50 \\
\hline CNA0006955 & 13,85 & Irrigado & Brasil (LCI) & 2.320 & 92 & - & - & 18,79 \\
\hline CA880070 & 13,80 & Sequeiro & Brasil (VT) & 3.189 & 113 & 148 & 107 & 32,25 \\
\hline
\end{tabular}

Fonte: Coleção Nuclear de Arroz da Embrapa (2010). (1) Dados não obtidos. 


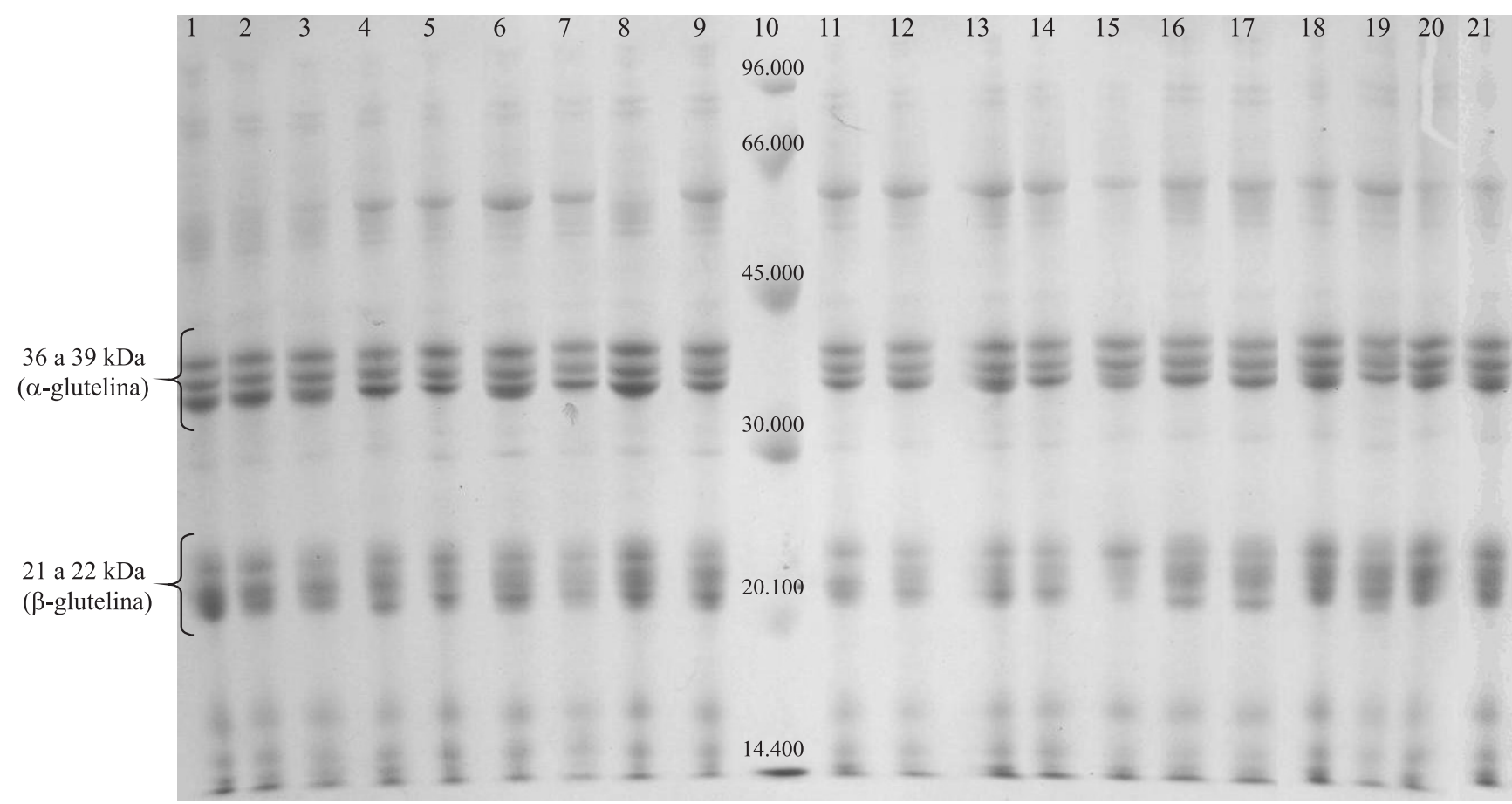

Figura 3. SDS-PAGE dos 20 acessos com maior teor de proteínas da Coleção Nuclear de Arroz da Embrapa (CNAE). Linha 1, CNA0000798; linha 2, BR IRGA 409; linha 3, CA880070; linha 4, CA840026; linha 5, CA810017; linha 6, CNA0003417; linha 7, CA780391; linha 8, CNA0000923; linha 9, CNA0008416; linha 10, marcador de massa molecular (Da); linha 11, ORYZICA 1; linha 12, CICA 7; linha 13, CNA0007408; linha 14, BR IRGA 413; linha 15, ELONI; linha 16, CNA0006130; linha 17, CA780284; linha 18, CNA0004617; linha 19, CNA0006955; linha 20, CNA0003195; linha 21, CNA0005853. Os acessos das linhas $6,13,15,18,20$ e 21 apresentam a fração glutelina do tipo $\alpha-4$.

\section{Conclusões}

1. Existe ampla variabilidade para o teor de proteína total de reserva do grão nos acessos da Coleção Nuclear de Arroz da Embrapa (CNAE).

2. A quantidade de proteína total de reserva não está relacionada com a origem dos acessos na CNAE (variedades tradicionais, linhagens e cultivares introduzidas ou linhagens e cultivares brasileiras), ou com o sistema de cultivo (irrigado, sequeiro ou facultativo).

3. Dois grupos de genótipos apresentam alto potencial para uso no melhoramento genético do arroz, um constituído por 103 acessos com teor de proteína total de reserva igual ou superior a $12 \%$, e outro constituído por seis acessos que apresentaram a fração glutelina do tipo $\alpha-4$.

\section{Agradecimentos}

À Coordenação de Aperfeiçoamento de Pessoal de Nível Superior, pela concessão de bolsa; e à
Financiadora de Estudos e Projetos do Ministério da Ciência e Tecnologia, pelo financiamento da pesquisa.

\section{Referências}

ABADIE, T.; CORDEIRO, C.M.T.; FONSECA, J.R.; ALVES, R. de B. das N.; BURLE, M.L.; BRONDANI, C.; RANGEL, P.H.N.; CASTRO, E. da M. de; SILVA, H.T. da; FREIRE, M.S.; ZIMMERMANN, F.J.P.; MAGALHÃES, J.R. Construção de uma coleção nuclear de arroz para o Brasil. Pesquisa Agropecuária Brasileira, v.40, p.129-136, 2005.

ARAÚJO, E.S. de; SOUZA, S.R. de; FERNANDES, M.S. Características morfológicas e moleculares e acúmulo de proteína em grãos de variedades de arroz do Maranhão. Pesquisa Agropecuária Brasileira, v.38, p.1281-1288, 2003.

BRADFORD, M.M. A rapid and sensitive method for the quantitation of microgram quantities of protein utilizing the principle of protein-dye binding. Analytical Biochemistry, v.72, p.248-254, 1976.

CAGAMPANG, G.B.; CRUZ, L.J.; ESPIRITU, S.G.; SANTIAGO, R.G.; JULIANO, B.O. Studies on the extraction and composition of rice protein. Cereal Chemistry, v.43, p.145-155, 1966. 
CASTRO, E. da M. de; VIEIRA, N.R. de A.; RABELO, R.R.; SILVA, S.A. da. Qualidade de grãos em arroz. Santo Antônio de Goiás: Embrapa Arroz e Feijão, 1999. 30p. (Embrapa Arroz e Feijão. Circular técnica, 34).

COLEÇÃO Nuclear de Arroz da Embrapa. Disponível em: $<$ http://www.cnpaf.embrapa.br/arroz/colecaonuclear/>. Acesso em: 15 dez. 2010.

CRUZ, C.D. Programa Genes: aplicativo computacional em genética e estatística. Viçosa: UFV, 1997. 442p.

FRANKEL, O.H. Genetic perspectives of germplasm conservation. In: ARBER, W.; LLIMENSEE, K.; PEACOCK, W.J.; STARLINGER, P. (Ed.). Genetic manipulation: impact on man and society. Cambridge: Cambridge University, 1984. p.161-170.

HUEBNER, F.R.; BIETZ, J.A.; WEBB, B.D.; JULIANO, B.O. Rice cultivar identification by high-performance liquid chromatography of endosperm proteins. Cereal Chemistry, v.67, p.129-135, 1990.

JAHAN, M.S.; KUMAMARU, T.; SATOH, H.; HAMID, A. Variation of glutelin seed storage protein in Bangladesh rice cultivars. Rice Genetics Newsletter, v.18, p.43-46, 2001.

JUGRAN, A.; BHATT, I.D.; RAWAL, R.S. Characterization of agro-diversity by seed storage protein electrophoresis: focus on rice germplasm from Uttarakhand Himalaya, India. Rice Science, v.17, p.122-128, 2010.

JULIANO, B.O. Polysaccharides, proteins and lipids of rice. In: JULIANO, B.O. (Ed.). Rice: chemistry and technology. $2^{\text {nd }}$ ed. St. Paul: The American Association of Cereal Chemists, 1985. p.17-57.

KAMESWARA RAO, N.; JACSKON, M.T. Seed longevity of rice cultivars and strategies for their conservation in genebanks. Annals of Botany, v.77, p.251-260, 1996.

KAMESWARA RAO, N.; JACSKON, M.T. Variation in seed longevity of rice cultivars belonging to different isozyme groups. Genetic Resources and Crop Evolution, v.44, p.159-164, 1997.

KHUSH, G.S. Origin, dispersal, cultivation and variation of rice. Plant Molecular Biology, v.35, p.25-34, 1997.
KOUTROUBAS, S.D.; MAZZINI, F.; PONS, B.; NTANOS, D.A. Grain quality variation and relationship with morpho-physiological traits in rice (Oryza sativa, L.) genetic resources in Europe. Field Crops Research, v.86, p.115-130, 2004.

KRISHNAN, H.B.; WHITE, J.A. Morphometric analysis of rice seed protein bodies: implication for a significant contribution of prolamine to the total protein content of rice endosperm. Plant Physiology, v.109, p.1491-1495, 1995.

LAEMMLI, U.K. Cleavage of structural proteins during the assembly of the head of bacteriophage T4. Nature, v.227, p.680-685, 1970 .

LU, K.; LI, L.; ZHENG, X.; ZHANG, Z.; MOU, T.; HU, Z. Genetic dissection of amino acid content in rice grain. Journal of the Science of Food and Agriculture, v.89, p.2377-2382, 2008.

OSBORNE, T.B. The vegetable proteins. London: Longmans Green, 1924. 154p.

OSZVALD, M.; TÖMÖSKÖZIA, S.; LARROQUE, O.; KERESZTÉNYIB, E.; TAMÁS, L.; BÉKES, F. Characterization of rice storage proteins by SE-HPLC and micro z-arm mixer. Journal of Cereal Science, v.48, p.68-76, 2008.

PEREIRA, D.P.; BANDEIRA, D.L.; QUINCOZES, E. da R.F. (Ed.). Cultivo do arroz irrigado no Brasil. Disponível em: <http://sistemasdeproducao.cnptia.embrapa.br/FontesHTML/ Arroz/ArrozIrrigadoBrasil/cap01.htm>. Acesso em: 15 mar. 2010.

SAS INSTITUTE. SAS language and procedures: usage. Version 6. Cary: SAS Institute, 1995. 373p.

SHEWRY, P.R.; HALFORD, N.G. Cereal seed storage protein: structures, properties and role in grain utilization. Journal of Experimental Botany, v.53, p.947-958, 2002.

SHOTWELL, M.A.; LARKINS, B.A. The biochemistry and molecular biology of seed storage proteins. The Biochemistry of Plants: a Comprehensive Treatise, v.15, p.297-345, 1989.

VAN HINTUM, T.J.L.; BROWN, A.H.D.; SPILLANE, C.; HODGKIN, T. Core collections of plant genetic resources. Rome: IPGRI, 2000. 48p. (IPGRI. Technical bulletin, 3).

Recebido em 11 de junho de 2010 e aprovado em 16 de novembro de 2010 